\title{
Exploration of Development Thoughts on Equipment Manufacturing Industry Based on Information Technology
}

\author{
Junliang Wang \\ Logistics Academy of Chinese people's Liberation Army, Beijing, 100858, \\ China
}

\begin{abstract}
At present, China's equipment manufacturing industry is still in the low development level. The application of information technology can bring about a multiplication effect, which can effectively improve the level of equipment manufacturing industry. This paper focuses on the application of information technology in the development fields of equipment manufacturing industry, including the design, production, marketing and supply chain, to contribute for the upgrading of equipment manufacturing industry in China.

Keywords:equipment manufacturing industry, information technology, intelligent manufacturing

\section{Concept of equipment manufacturing industry}

Equipment manufacturing industry, also known as the equipment industry, is a collection of all kinds of technology manufacturing equipment industry to meet the needs of the development of national economy and national security. It is generally believed that the manufacturing industry consists of the equipment manufacturing industry and the final consumer goods manufacturing industry. Equipment manufacturing industry is a general term for the production of technical equipment for the simple reproduction and expansion of the national economy. Generally speaking, the production process depends on the technical elements and dependence on labour is inversely proportional, that only when the technical level is low.The labour force will hold, but the equipment manufacturing industry is different, labour-intensive and technology intensive
\end{abstract}


exist at the same time. The reason is: the production of the equipment manufacturing industry is mainly carried out by products in a single manufacturing, non-standard manufacturing, project manufacturing mode, the production organization mode and the final consumer goods manufacturing production organization mode is very different. The final consumer goods manufacturing products can be more batch, production line, and the equipment manufacturing industry is not a small number of workers in the custody of a few production lines can make the production process running smoothly. Therefore, the equipment manufacturing industry not only is in the capital intensive, technology intensive, but also is the labour-intensive industry. The technology and human needs are very strong. Because of this, the equipment manufacturing industry was on investment, technological progress, employment driven effect is extremely, is indeed a pillar industry of the national economy. Obviously, the core of the equipment manufacturing industry belongs to the manufacturing industry of the national economy. Equipment manufacturing industry plays a very important role in the national economy. A highly developed equipment manufacturing industry is an essential condition for the realization of industrialization and an important indicator of national competitiveness.

\section{Necessity of reforming equipment manufacturing industry based on information technology}

The products of equipment manufacturing industry applied the information technology change profoundly the human society and lifestyle. Equipment manufacturing industry is responsible for the national economy and industrial upgrading to provide major equipment and modern production tools. With the rapid development of information technology, it provides a great space and great prospect for the upgrading and sustainable development of equipment manufacturing industry. The use of information technology to transform the equipment manufacturing industry, which is the application of information technology and spread to the equipment manufacturing industry to improve design, manufacturing, service capabilities of the equipment manufacturing industry,. Because of its own characteristics, equipment manufacturing industry has many unique requirements for information technology. The equipment manufacturing industry including the manufacture of major technical equipment, high-tech equipment manufacturing industry, involving cutting-edge equipment, these devices related to high temperature and high pressure conditions, the information technology requirements are very strict and special. Because the information technology of the equipment manufacturing industry is often unique and not universal, it is necessary to cooperate with multi-disciplinary and cross industry technical resources. China's equipment manufacturing industry and equipment manufacturing industry and information technology enterprises, the lack of effective integration of resources and business convergence, demand is unknown, the lack of information, cooperation channels, technical cooperation to organize multi-disciplinary, cross industry. In the process of using the information technology to transform the equipment manufacturing industry, it 
involves not only the transformation of the traditional industry and the mode of production and management, but also the research and development of new products and technologies. The research and development of new products often requires the support of the state and enterprises.

\section{Directions of transforming equipment manufacturing industry based on information technology}

\subsection{Reform design based on information technology}

With the help of the internet, a new global system of industrial division of labor and the division of labor is being formed. The enterprises can build or use existing platform, publish research and development needs, ideas and wisdom of collecting customers and external personnel, socialization, product innovation to create value diversification. Based on this, manufacturing, service transactions and other resource allocation system will also change with the division of labor organization and accelerate organizational innovation. The design is a highly creative activity, which puts forward higher requirements for the enterprise gathering resources and integrated innovation. Internet platform for enterprise gathering, docking various types of social innovation resources to provide an effective carrier to help companies improve its efficiency, reduce innovation costs, and quickly enhance the core competitiveness of the market. Home appliances, clothing and other industries closely linked with the consumer side to build an open network platform, smooth and user interaction channels, extensive collection of user needs, the development of on-demand customized business. The large enterprises further explored the development of crowdsourcing model, based on the actual needs of consumers to grasp, through the construction of interactive innovation community to attract employees within the enterprise and social research institutions to carry out creative design of products, issued a notebook and a series of internet innovative products. Machinery, aviation and other far away from the consumer side of the industry focus on gathering and sharing of production factors and resources to achieve industrial chain upstream and downstream collaborative design. Commercial Aircraft Corporation of China Ltdefficiently coordinated dozens of thousands of aircraft designers all over the world to complete the online collaborative design, greatly shortening the development cycle. The development of information technology provides strong support for the designof equipment manufacturing industry.

\subsection{Reform production based on information technology}

Information technology also makes the production mode of manufacturing enterprises has undergone fundamental changes. Lean production, agile manufacturing, concurrent engineering, mass customization production are all the result of information technology. Electronic commerce, supply chain management, networked manufacturing and so cannot do without the information 
technology, it is also constantly improve these new information and associated production organization to the competitiveness of the equipment manufacturing industry, new level continues to rise, be able to meet the personalized needs of users. From the history of industrialization, the application of information technology, there is no modern equipment manufacturing industry. Information technology drives the automation and digitization of design, manufacture and management, and makes the process of product design, manufacturing and management. Information technology accelerates the flow and optimal allocation of manufacturing resources on a global scale. For the production of the whole process, the whole industry chain, product life cycle, the implementation of intelligent manufacturing and other major projects, quality management and support enterprises to deepen the integration of the Internet, online measurement, online detection etc. promote the quality control of the whole industry chain, vigorously develop the new production mode of networked collaborative manufacturing. Support enterprises to use the Internet to collect and connect the user's individual needs, to carry out research and development, production, service and business model innovation based on personalized products, and promote the precise matching of supply and demand.

\subsection{Reform marketing based on information technology}

From the current development level of China manufacturing industry and internet technology, raw material procurement, human resources construction, production, marketing and other products, the most popularinternet technology is the product marketing. Part of the reason is the Internet technology and manufacturing product marketing has the characteristics of natural fusion, another part is the manufacturing industry downturn of the market is full of anxiety and desire for entrepreneurs' product outlet. At present, the Internet has become an important marketing tool for modern enterprise, establish the enterprise portal website is an important means of enterprise network marketing strategy, it is not just selling products and publish procurement needs of enterprises at the same time. The establishment of enterprise website to enhance corporate image, the company has the network communication ability, can be introduced, the company's products and demand release, can provide a good basis for enterprises to establish their own customer service platform. Through the establishment of enterprise information portal, the establishment of customer demand, timely collection of market bidding information, customer information to the scientific order, to project sales record, to help enterprises accurately determine customer consumption standards, develop new sales opportunities, establish a close relationship between the enterprise and the customer and help, make the enterprise with the most appropriate the products in the most appropriate time to meet customer needs. The enterprise will be transformed into a market-oriented new enterprise. With the mobile Internet to further promote the rapid popularization of mobile terminals, making the traditional marketing model is also undergoing tremendous changes. Network marketing has become a keen marketing platform. 


\subsection{Reform supply chain based on information technology}

The competition in twenty-first century is not the competition among equipment manufacturing enterprises, but the competition among supply chains of equipment manufacturing industry. Only through continuous information technology, China's equipment manufacturing industry can form a symbiotic environment with large manufacturing enterprises as the core. Now, part of the manufacturing enterprises often only take into account the maximization of their own interests, excessive squeeze upstream suppliers and downstream vendors' revenue. This is very dangerous. The competition of equipment manufacturing industry is the competition of two supply chains. The information supply chain of equipment manufacturing industry is a great waste of social resources. Large scale manufacturing enterprises a lot of information such as spare parts, raw materials inventory information is very important for suppliers, inventory, sales, sales of large enterprise customer information is very important for manufacturing enterprise is, but if the partners do not take timely and transparent information sharing strategy, supply chain information in certain aspects of the formation of a block of information. In order to solve this problem, the equipment manufacturing industry must first have the idea of international management and real-time enterprise, and realize the supply chain management of equipment manufacturing industry by means of network. The raw materials and accessory products, products in the internal and external circulation quickly; inventory, sales, customer information such as rapid exchange in the supply chain; only in this way, manufacturing enterprises can quickly develop new products, quickly adjust production and procurement plan, efficient organization and production, inventory and timely delivery to the local sales. In the information supply chain of equipment manufacturing industry, the information content supply chain of equipment manufacturing industry.

\section{Conclusion}

The equipment manufacturing industry is the foundation of the manufacturing industry, which plays an important role in elevating the economy of our country. Information technology can transform the equipment manufacturing industry in the fields of design, production, marketing and supply chain to enhance the level of equipment manufacturing industry to turn China from a big manufacturing country to a strong manufacturing country.

\section{References}

[1]Dev C A G, Kumar V S S. Analysis on critical success factors for agile manufacturing evaluation in original equipment manufacturing industry-an AHP approach, Chinese Journal of Mechanical Engineering, 29(5), pp.880-888, 2016. [2]Liu Q, Wang Y, Asymmetric Game Analysis of China's Equipment Manufacturing Industry Hollowing-Out, Journal of Research in Business, Economics and Management, 5(4), pp. 654-663, 2016. 
[3]Chi Y, Zhang J, The Experience and Enlightenment of American High-End Equipment Manufacturing Industry to China, American Journal of Industrial and Business Management, 3(08), pp. 681, 2013.

[4]Bourassa D, Gauthier F, Abdul-Nour G, Equipment failures and their contribution to industrial incidents and accidents in the manufacturing industry, International journal of occupational safety and ergonomics, 22(1): pp. 131-141, 2016. 